\title{
Prevalence of $q a c A / B$ Genes and Mupirocin Resistance Among Methicillin-Resistant Staphylococcus aureus (MRSA) Isolates in the Setting of Chlorhexidine Bathing Without Mupirocin
}

\author{
David K. Warren, MD, MPH; ${ }^{1}$ Martin Prager, MD ${ }^{1}$ Satish Munigala, MBBS, MPH; ${ }^{1}$ Meghan A. Wallace, BS; ${ }^{2}$ \\ Colleen R. Kennedy; ${ }^{2}$ Kerry M. Bommarito, PhD; ${ }^{1}$ John E. Mazuski, MD, PhD; ${ }^{3}$ Carey-Ann D. Burnham, $\mathrm{PhD}^{2}$
}

овјестіve. We aimed to determine the frequency of $q a c A / B$ chlorhexidine tolerance genes and high-level mupirocin resistance among MRSA isolates before and after the introduction of a chlorhexidine (CHG) daily bathing intervention in a surgical intensive care unit (SICU).

DESIGN. Retrospective cohort study (2005-2012).

SETTING. A large tertiary-care center.

PAtients. Patients admitted to SICU who had MRSA surveillance cultures of the anterior nares.

methods. A random sample of banked MRSA anterior nares isolates recovered during (2005) and after (2006-2012) implementation of a daily CHG bathing protocol was examined for qacA/B genes and high-level mupirocin resistance. Staphylococcal cassette chromosome mec (SCCmec) typing was also performed.

RESULTS. Of the 504 randomly selected isolates (63 per year), $36(7.1 \%)$ were qacA/B positive $(+)$ and $35(6.9 \%)$ were mupirocin resistant. Of these, $184(36.5 \%)$ isolates were SCCmec type IV. There was a significant trend for increasing qacA/B $(P=.02$; highest prevalence, $16.9 \%$ in 2009 and 2010) and SCCmec type IV $(P<.001$; highest prevalence, $52.4 \%$ in 2012$)$ during the study period. qacA/B $(+)$ MRSA isolates were more likely to be mupirocin resistant ( 9 of $36[25 \%] q a c A / B(+)$ vs 26 of $468[5.6 \%] q a c A / B(-) ; P=.003$ ).

CONCLUSIONs. A long-term, daily CHG bathing protocol was associated with a change in the frequency of qacA/B genes in MRSA isolates recovered from the anterior nares over an 8 -year period. This change in the frequency of qacA/B genes is most likely due to patients in those years being exposed in prior admissions. Future studies need to further evaluate the implications of universal CHG daily bathing on MRSA $q a c A / B$ genes among hospitalized patients.

Infect Control Hosp Epidemiol 20 16;37:590-597

Methicillin-resistant Staphylococcus aureus (MRSA) is a major cause of healthcare-associated infections. ${ }^{1-3}$ Compared with methicillin-susceptible strains, MRSA is associated with increased risk of adverse health outcomes and increased treatment costs. $^{4,5}$ Multiple studies have shown that MRSA nasal colonization is a risk factor for subsequent MRSA infection. ${ }^{6-8}$ Interventions to interrupt MRSA transmission among hospitalized patients include active surveillance for colonization and contact precautions. 9,10

Recently, the use of chlorhexidine (CHG)-based body wash, either alone or in combination with intranasal antibiotics such as mupirocin, has been demonstrated to reduce the incidence of MRSA transmission and subsequent infection among hospitalized patients. ${ }^{11-13}$ However, widespread use of chlorhexidine may result in the selection of bacteria that are chlorhexidine tolerant, with the potential to limit the effectiveness of this intervention in the future. In $S$. aureus, chlorhexidine tolerance is associated with the qac gene family $(q a c A / B)$, which code for efflux pumps capable of extruding chlorhexidine and other biocidal compounds from the cell. $^{14-17}$ The presence of $q a c A / B$ has been associated with elevated minimum bactericidal concentrations for chlorhexidine and MRSA decolonization protocol failures. ${ }^{18,19}$ The implementation of a daily topical chlorhexidine antiseptic protocol among ICU patients resulted in the selection of a qacA/B-positive $(+)$ MRSA strain, while the transmission of other MRSA strains was reduced during the 2 -year period. ${ }^{20}$ Some plasmids harboring the qac genes may contain additional

Affiliations: 1. Department of Medicine, Washington University School of Medicine, St. Louis, Missouri; 2. Department of Pathology \& Immunology, Washington University School of Medicine, St. Louis, Missouri; 3. Department of Surgery, Washington University School of Medicine, St. Louis, Missouri.

PREVIOUS PRESENTATION: Data from this study were presented in part as an abstract on October 9th 2014 at the 2014 ID Week meeting in Philadelphia, Pennsylvania.

Received September 17, 2015; accepted December 20, 2015; electronically published February 2, 2016

(c) 2016 by The Society for Healthcare Epidemiology of America. All rights reserved. 0899-823X/2016/3705-0014. DOI: 10.1017/ice.2016.1 
antibiotic resistance genes. ${ }^{14,17,21}$ In vitro evidence that CHG may induce selective pressure in clinical MRSA isolates ${ }^{18,20}$ highlights the importance of antiseptic tolerance evaluation as part of infection control practices.

Mupirocin, a topical antibiotic, is widely used for treatment of uncomplicated skin and soft-tissue infections and MRSA decolonization. Resistance to mupirocin is broadly classified as low-level resistance (typically defined as having a minimum inhibitory concentration [MIC] of $8-256 \mathrm{mg} / \mathrm{L}$ ), and highlevel resistance (MIC $\geq 512 \mathrm{mg} / \mathrm{L})^{18,20,22,23}$ is most commonly conferred by the plasmid-borne тирA gene, although other mechanisms have been reported. ${ }^{24-26}$ Mupirocin resistance has been associated with reduced effectiveness of decolonization strategies. ${ }^{27}$ Its prevalence is variable, ranging from $4 \%$ among MRSA isolates in Canadian hospitals to as much as $80 \%$ in a Swiss hospital in the context of widespread mupirocin use. ${ }^{28,29}$

Based upon studies of chlorhexidine-based daily bathing protocols and subsequent MRSA infection, this practice is becoming more widespread in hospitals. However, the longterm effects of daily chlorhexidine bathing on the prevalence of $q a c A / B$ resistance genes in MRSA isolates in the hospital setting is unknown.

The objective of this study was to determine changes in the frequency of $q a c A / B$ gene carriage and mupA-mediated high-level mupirocin resistance among nasal MRSA isolates recovered from active surveillance nasal cultures in the 8-year period during and following implementation of a universal chlorhexidine bathing intervention in a surgical intensive care unit (SICU).

\section{METHODS}

\section{Study Design and Setting}

We conducted a retrospective cohort study of patients admitted between 2005 and 2012 to the 24-bed surgical intensive care unit of Barnes-Jewish Hospital (BJC), a 1,250-bed tertiary-care hospital in St. Louis, Missouri.

\section{Chlorhexidine Bathing Intervention}

On June 1, 2005, the SICU implemented a daily chlorhexidine bathing protocol, replacing a once-daily bath with nonmedicated soap and water. Daily water basin baths used $4 \%$ chlorhexidine gluconate soap (Exidine, Cardinal Health, McGraw Park, IL). Compliance, as measured by number of soap bottles used per patient day, was $>90 \%$. Chlorhexidine soap was diluted in water to achieve a final concentration of approximately $0.125 \%(1,250 \mu \mathrm{g} / \mathrm{mL})$. There was no routine use of intranasal mupirocin during this time period.

\section{Data Collection}

All patients admitted to the SICU had a swab of the anterior nares obtained for MRSA surveillance cultures per the hospital infection prevention policy. Patients who stayed for $>2$ days had nasal swabs weekly and at SICU discharge. All MRSA isolates were saved from 2005 to 2012. For this study, isolates from patients admitted to the SICU in 2005 were considered to be collected in the implementation period, and the post-implementation period was 2006-2012.

We estimated a MRSA qacA/B baseline prevalence of $1 \%$, based upon a study of household prevalence in the Saint Louis community. ${ }^{30}$ Thus, we estimated that 63 randomly selected isolates per year (504 total) would be required to detect a $1 \%$ per year increase in prevalence of $q a c A / B$ positivity during the study period $(\beta=0.80$ and $\alpha=0.05)$. Random sampling was done by computer analysis using SPSS version 20 (IBM SPSS, Chicago, IL).

Patient demographics, length of stay in days (LOS, median [interquartile range, IQR]), previous hospitalization history, presence of comorbidities and other characteristics were obtained from the Barnes-Jewish Hospital (BJC) medical informatics database for all patients whose isolates were included in this study. Patients with negative admission cultures but subsequently had a positive nasal MRSA culture during the SICU admission were considered to have ICU-acquired MRSA.

\section{Microbiological Methods}

MRSA culture testing was performed as described previously. ${ }^{31}$ Isolates were stored in skim milk at $-70^{\circ} \mathrm{C}$ prior to analysis. Selected isolates were subcultured on sheep's blood agar. MRSA was confirmed using cefoxitin disk diffusion testing according to CLSI standards. ${ }^{32}$ Selected samples underwent amplification $^{14}$ of the $q a c A / B$ genes using a polymerase chain reaction (PCR) with the following primers: F: 5'-CTA TGG CAA TAG GAG ATA TGG TGT-3', R: 5'-CCA CTA CAG ATT CTT CAG CTA CAT G-3'. As a confirmatory test, a second set of $q a c A / B$ PCR was performed on all initially positive isolates. ${ }^{30}$

We performed mupirocin phenotypic susceptibility testing by Kirby-Bauer disk diffusion using a $200-\mu \mathrm{g}$ mupirocin disk (Oxoid, Hampshire, UK) on Mueller-Hinton agar (Hardy Diagnostics, Santa Maria, CA). ${ }^{23}$ Isolates with no zone of inhibition around the mupirocin disk were classified as mupirocin resistant. All mupirocin-resistant isolates underwent PCR amplification for detection of $m u p A^{30,32,33}$ using the following primers: F: 5'-TAT ATT ATG CGA TGG AAG GTT GG-3', R: AAT AAA ATC AGC TGG AAA GTG TTG-3'. All MRSA isolates underwent SCCmec typing using a multiplex PCR that could detect and resolve SCCmec types I through V. ${ }^{34}$

\section{Statistical Analysis}

The Cochran-Armitage trend test was used to compare $q a c A / B$ and SCCmec type frequencies by year. Statistical significance was tested using the Mantel-Hansel $\chi^{2}$ test, univariate logistic regression, Student $t$ test, or Wilcoxon signed rank test as appropriate. A 2 -sided $P \leq .05$ was considered significant. 
Statistical analyses were performed with SPSS and SAS v9.3 (SAS Institute, Cary, NC).

This study was approved by the Washington University Human Research Protection Office.

\section{RES ULTS}

\section{Patient Characteristics}

Overall, 1,880 banked MRSA isolates recovered from the anterior nares from 2005 to 2012 were available for testing. In total, 41 isolates were excluded: 27 were repeat isolates from the same patient, 13 were methicillin-susceptible $S$. aureus on confirmatory testing, and 1 was from a patient who was not in the SICU at the time of testing (Figure 1). After exclusions, MRSA isolates from 504 randomly selected patients (63 per year) were included in the study (Figure 1). Characteristics of the study participants are shown in Table 1 . Notably, $70 \%$ of the MRSA isolates were obtained within the first 2 days of SICU admission. Among all the MRSA isolates, 36 (7.1\%) were $q a c A / B(+)$. There was no significant difference in the prevalence of $q a c A / B$ MRSA isolates among patients in whom MRSA was initially recovered $>2$ days after ICU admission $(10$ [27.8\%] qac $A / B(+)$ vs 144 [30.8\%] qac $A / B(-) ; P=.85)$. Also, we found no significant difference in the prevalence of $q a c A / B$ positivity among MRSA isolates relative to transfer

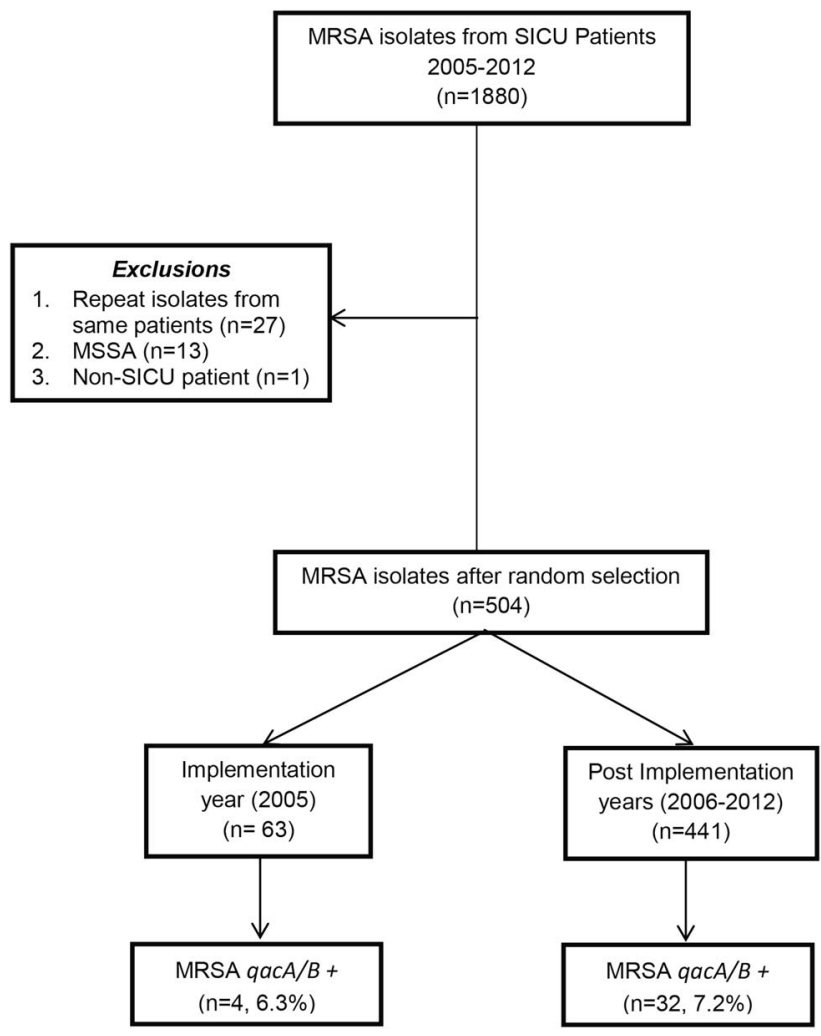

FIGURE 1. Selection of study population. MRSA, methicillinresistant S. aureus; MSSA, methicillin-susceptible S. aureus; SICU, surgical intensive care unit. from another hospital or facility (11 [30.5\%] $q a c A / B(+)$ vs 91 [19.5\%] qacA/B(-); $P=.13)$. Compared with patients colonized with $q a c A / B(-)$ MRSA isolates, patients colonized with $q a c A / B(+)$ MRSA isolates were less likely to have diabetes $(5.6 \%$ vs $22.3 \% ; P=.02)$ or congestive heart failure (0 vs $13.7 \% ; P=.009$ ) (Table 2 ).

\section{Prevalence of $q a c A / B(+)$ and $m u p A(+)$}

The prevalence of $q a c A / B(+)$ MRSA isolates was $6.2 \%$ in the implementation year, then this rate fell to $0-1.5 \%$ between 2006 and 2008. The prevalence then increased to $16.9 \%$ for 2 years (2009 and 2010) and subsided thereafter, indicating a significant trend for $q a c A / B(P=.02)$ (Figure 2). Of the MRSA isolates tested, $35(6.9 \%)$ were mupirocin resistant by the diffusion disk method. All of the phenotypically mupirocinresistant isolates were $m u p A(+)$.

The prevalence $q a c A / B(+)$ isolates obtained $<2$ days showed a significant trend compared with isolates obtained $\geq 2$ days of SICU admission $(P=.04$ for $q a c A / B<2$ days after

TABLE 1. Patient Characteristics

\begin{tabular}{lc}
\hline Patient Characteristic & No. $(\%)(\mathrm{N}=504)$ \\
\hline Age, y, median (IQR) & $63(48-75)$ \\
Female gender & $207(42)$ \\
Race & \\
White & $375(74.4)$ \\
Non-white & $129(25.6)$ \\
Medical comorbidities & \\
CHF & $64(12.7)$ \\
COPD & $107(21.2)$ \\
Diabetes mellitus & $106(21)$ \\
Malignancy & $79(15.7)$ \\
Cirrhosis & $19(3.8)$ \\
Solid organ transplant & $6(1.2)$ \\
ESRD & $9(1.8)$ \\
HIV infection & $4(0.8)$ \\
Previous admissions to BJH in prior 12 months & \\
0 & $167(33)$ \\
1-5 & $201(40)$ \\
$>5$ & $136(27)$ \\
Central venous catheter in place & $151(30)$ \\
Days from ICU admission to MRSA (+) culture & \\
1-2 d & $350(70)$ \\
>2 d & $154(30)$ \\
Outcomes & \\
ICU LOS, d, median (IQR) & $3(2-9)$ \\
Hospital LOS, d, median (IQR) & $14(7-26)$ \\
In-hospital mortality & $78(15.5)$ \\
\hline
\end{tabular}

NOTE. IQR, interquartile range; MRSA, methicillin-resistant S. aureus; CHF, congestive heart failure; COPD, chronic obstructive pulmonary disease; ERSD, end-stage renal disease; HIV, human immunodeficiency virus; BJH, Barnes-Jewish Hospital; ICU, intensive care unit; LOS, length of stay. 
TABLE 2. Comparison of Study Participants with MRSA Intranasal Isolates by $q a c A / B$ Status

\begin{tabular}{|c|c|c|c|}
\hline & $\begin{array}{c}q a c A / B(+) \\
\text { MRSA, No. } \\
(\%)(\mathrm{n}=36)\end{array}$ & $\begin{array}{c}q a c A / B(-) \\
\text { MRSA, No. } \\
(\%)(\mathrm{n}=468)\end{array}$ & $\begin{array}{c}P \\
\text { Value }\end{array}$ \\
\hline Age, y, median (IQR) & $60(41-71)$ & $63(49-75)$ & .24 \\
\hline Female gender & $16(44.4)$ & $191(40.8)$ & .72 \\
\hline \multicolumn{4}{|l|}{ Race } \\
\hline White & $31(86.1)$ & $344(73.5)$ & .11 \\
\hline Non-white & $5(13.9)$ & $124(26.5)$ & \\
\hline \multicolumn{4}{|l|}{ Medical comorbidities } \\
\hline $\mathrm{CHF}$ & 0 & $64(13.7)$ & .009 \\
\hline COPD & $6(16.7)$ & $101(21.6)$ & .67 \\
\hline Diabetes mellitus & $2(5.6)$ & $104(22.2)$ & .02 \\
\hline Malignancy & $3(8.3)$ & $76(16.2)$ & .33 \\
\hline Cirrhosis & 0 & $19(4.1)$ & .38 \\
\hline Solid organ transplant & 0 & $6(1.3)$ & 1.00 \\
\hline ESRD & $1(2.8)$ & $8(1.7)$ & .48 \\
\hline HIV infection & 0 & $4(0.9)$ & $\ldots$ \\
\hline \multicolumn{4}{|l|}{$\begin{array}{l}\text { Previous admissions to } \mathrm{BJH} \text { in } \\
\text { prior } 12 \mathrm{mo}^{\mathrm{a}}\end{array}$} \\
\hline 0 & $11(30.5)$ & $156(33.3)$ & .85 \\
\hline $1-5$ & $21(58.3)$ & $180(38.5)$ & .11 \\
\hline$>5$ & $4(11.1)$ & $132(28.2)$ & .25 \\
\hline $\begin{array}{l}\text { Central venous catheter in } \\
\text { place }\end{array}$ & $11(30.6)$ & $140(30)$ & 1.00 \\
\hline \multicolumn{4}{|l|}{$\begin{array}{l}\text { Days from ICU admission to } \\
\text { MRSA }(+) \text { culture }\end{array}$} \\
\hline Days 1-2 & $26(72.2)$ & $324(69.2)$ & .85 \\
\hline$>2$ days & $10(27.8)$ & $144(30.8)$ & \\
\hline \multicolumn{4}{|l|}{ SCCmec type } \\
\hline Type IV & $15(41.7)$ & $169(35.9)$ & .47 \\
\hline Other & $21(58.3)$ & $299(64.1)$ & \\
\hline \multicolumn{4}{|l|}{ Outcomes } \\
\hline ICU LOS, d, median (IQR) & $5(2-15)$ & $3(2-9)$ & .12 \\
\hline $\begin{array}{l}\text { Hospital LOS, d, median } \\
\text { (IQR) }\end{array}$ & $16(9-32)$ & $14(7-26)$ & .74 \\
\hline In-hospital mortality & $2(5.6)$ & $76(16.9)$ & .09 \\
\hline \multicolumn{4}{|l|}{ Admission referral source } \\
\hline Physician or ER & $25(69.5)$ & $377(80.5)$ & .13 \\
\hline $\begin{array}{l}\text { Other acute care hospital or } \\
\text { other facility }\end{array}$ & $11(30.5)$ & $91(19.5)$ & \\
\hline
\end{tabular}

NOTE. IQR, Interquartile range; MRSA, methicillin-resistant S. aureus; CHF, congestive heart failure; COPD, chronic obstructive pulmonary disease; ERSD, end-stage renal disease; HIV, human immunodeficiency virus; BJH, Barnes-Jewish Hospital; ICU, intensive care unit; LOS, length of stay; ER, emergency room.

${ }^{\mathrm{a}}$ Univariate logistic regression (No previous admission as a reference group).

admission vs $P=.29$ for $q a c A / B \geq 2$ days after admission) (Figure 3).

Among all isolates, $9(1.8 \%)$ were both $q a c A / B(+)$ and $\operatorname{mup} A(+)$. These isolates occurred in $2005(\mathrm{n}=1), 2008$ $(\mathrm{n}=1), 2009(\mathrm{n}=3), 2010(\mathrm{n}=3)$, and $2012(\mathrm{n}=1)$. MRSA isolates that were $q a c A / B(+)$ were more likely to be $m u p A(+)$ than $q a c A / B(-)$ isolates $(25 \%$ vs $5.6 \% ; P=.003)$ (Table 3$)$.

\section{Characteristics of $q a c A / B(+)$ Isolates Recovered by Year}

Due to the observed significant trends, we evaluated the data regarding admission source (ie, referred by physician, emergency room (ER), or another facility or acute care facility), hospital LOS, LOS prior to SICU admission, and rate of hospital admissions (previous 12 months) for patients with qac $A / B(+)$ isolates obtained during 2009-2010 and compared them with all other years. We found no significant difference in the admission source (16 [72.7\%] vs 9 [64.3\%], $P=.72$ for admission by physician/ER), hospital stay prior to SICU admission $(1[0-6]$ vs $0[0-2], P=.23)$, or total hospital LOS (14.5 [9-23] vs 22 [7-39], $P=.11)$. However, compared with $q a c A / B(+)$ isolates from other study years, the $q a c A / B(+)$ isolates from 2009 and 2010 were more likely to have $\geq 1$ hospital admissions in the prior year (20 [90.9\%] vs 7 [50.0\%]; $P=.01$ ) (Table 4).

\section{Prevalence of SCCmec Types}

Of the 504 MRSA isolates tested, 10 (2\%) were SCCmec type I, $305(60.5 \%)$ were SCCmec type II, $3(0.6 \%)$ were SCCmec type III, $184(36.5 \%)$ were SCCmec type IV, and $2(0.4 \%)$ were SCCmec type V. The prevalence of MRSA isolates that were SCCmec type IV significantly increased from $23.8 \%$ in 2005 to $52.4 \%$ in $2012(P<.0001)$. There was no significant difference in the prevalence of $q a c A / B(+)$ by SCCmec type during the study period (Table 3 ).

\section{DISCUSSION}

In our 24-bed SICU, the prevalence of qacA/B genes associated with chlorhexidine tolerance changed in MRSA nasal isolates over the 8-year study period of daily patient bathing with chlorhexidine soap. This change was nonlinear and was associated with an increase in prevalence in years 5 and 6 of the study, then decreased in the remaining 2 years. A comparison of study patients from 2009 and 2010 versus patients from other study years revealed no significant difference in ICU and hospital LOS or rates of hospital admission in the prior 12 months. However, patients from these 2 years were more likely to have a MRSA isolate cultured from a nasal swab collected within the first 2 days of ICU admission (95 of 126 [75.4\%] vs 247 of 378 [66.9\%]; $P=.04)$. Our comparison of $q a c A / B(+)$ isolates from 2009 and 2010 with $q a c A / B(+)$ isolates from other study years also revealed no significant difference in admission source, hospital LOS and LOS prior to SICU admission; however, qacA/B(+ ) isolates from 2009 and 2010 were more likely to have $\geq 1$ hospital admissions in the prior year, suggesting a possibility of an expansion of qacA/B $(+)$ MRSA at BJH during this time period, which resulted in $q a c A / B(+)$ patients in those years being exposed in prior admissions. Daily CHG bathing was implemented in 2009 in the other 5 hospital ICUs but not on other inpatient units. There was no marked change in the prevalence of MRSA 


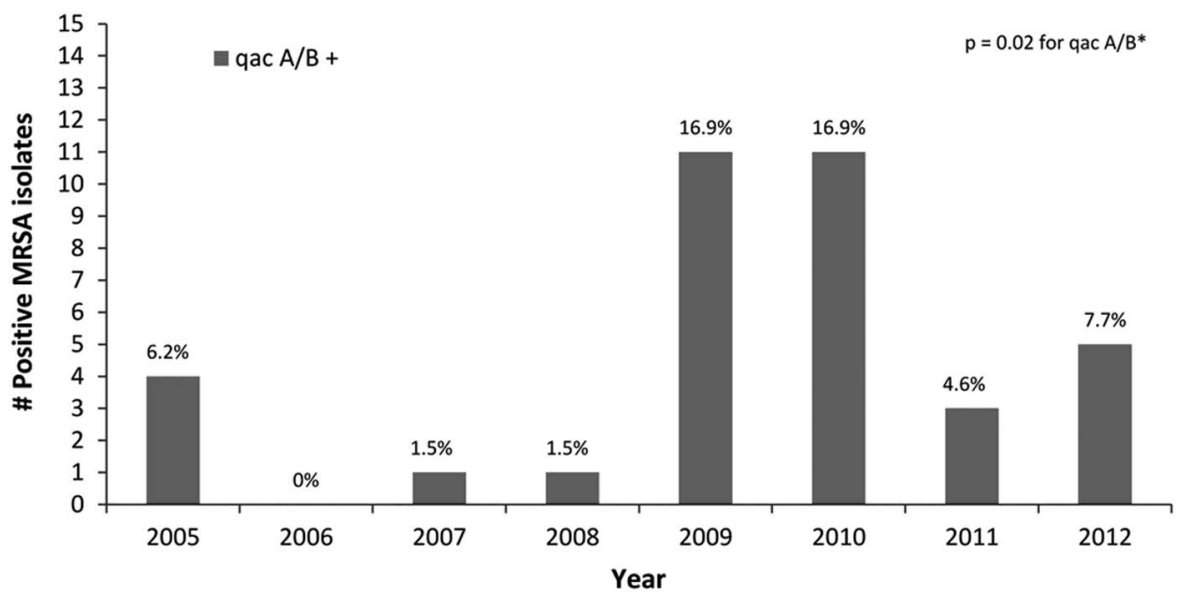

FIGURE 2. Prevalence of $q a c A / B(+)$ among sampled MRSA nasal isolates, per year (2005-2012). MRSA, methicillin-resistant S. aureus; p, $P$ value.

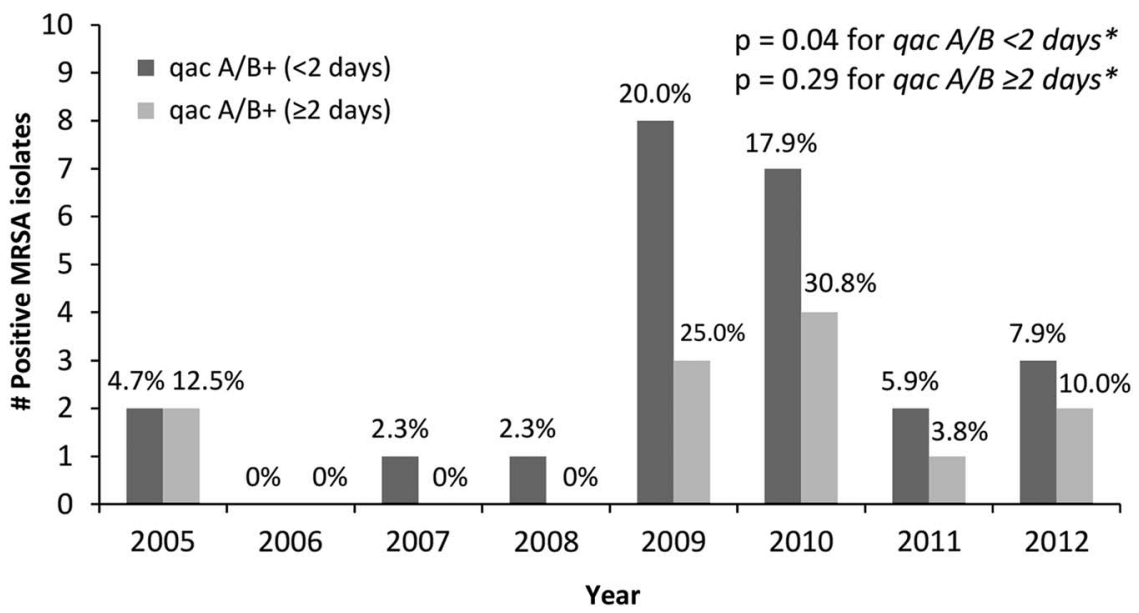

FIGURE 3. Annual prevalence of $q a c A / B(+)$ MRSA, stratified by detection $<2$ days $(n=24)$ versus $\geq 2$ days $(n=12)$ after ICU admission. MRSA, methicillin-resistant $S$. aureus; $\mathrm{p}, P$ value.

TABLE 3. Comparison of MRSA Isolate Characteristics by $q a c A / B$ Status

\begin{tabular}{lccl}
\hline & $\begin{array}{c}q a c A / B(+) \text { MRSA, } \\
\text { No. }(\%)(\mathrm{n}=36)\end{array}$ & $\begin{array}{c}\text { qacA/B(- }) \text { MRSA, } \\
\text { No. } \%)(\mathrm{n}=468)\end{array}$ & $P$ Value \\
\hline mupA $(+)$ & $9(25)$ & $26(5.6)$ & .003 \\
mupA $(-)$ & $27(75)$ & $442(94.4)$ & \\
SCCmec type & & & \\
I & $2(5.5)$ & $8(1.7)$ & .15 \\
II & $18(50.0)$ & $287(61.4)$ & .21 \\
III & 0 & $3(0.6)$ & .00 \\
IV & $15(41.7)$ & $169(36.1)$ & .59 \\
V & $1(2.8)$ & $1(0.2)$ & .13 \\
\hline
\end{tabular}

NOTE. MRSA, methicillin-resistant S. aureus; SCCmec, staphylococcal cassette chromosome mec.

isolates containing any of the SCCmec type's genetic element in these 2 years that would suggest a clonal MRSA outbreak in the ICU. We cannot rule out the possibility of dissemination of $q a c A / B$ due to horizontal transmission of a $q a c A / B$-containing plasmid among the endemic MRSA strains in the unit. ${ }^{35}$ However, the prevalence of this genetic element did not remain persistently elevated in the setting of stable daily chlorhexidine use throughout the post-implementation period. Our findings suggest that long-term daily chlorhexidine bathing at the concentration used in this ICU did not result in sustained, widespread dissemination of genes encoding for chlorhexidine tolerance.

The prevalence of high-level phenotypic mupirocin resistance among MRSA nasal isolates was $6.9 \%$ and remained stable. This finding is similar to that of an earlier study of nasal MRSA isolates from patients in this ICU from 2002 to 2004, which reported the high-level mupirocin resistance rate to be $8.6 \%{ }^{29}$ Intranasal mupirocin therapy was not systematically used in any area of the hospital during the study period. All high-level mupirocin-resistant MRSA isolates we tested contained mupA. Among the MRSA isolates tested, 9 (1.8\%) 
TABLE 4. Comparison of $q a c A / B(+)$ Isolates by Year

\begin{tabular}{|c|c|c|c|}
\hline & $\begin{array}{c}q a c A / B(+) \text { MRSA } \\
(2009,2010), \text { No. }(\%) \\
(\mathrm{n}=22)\end{array}$ & $\begin{array}{c}q a c A / B(+) \text { MRSA, All Other } \\
\text { Years, No. }(\%) \\
(\mathrm{n}=14)\end{array}$ & $\begin{array}{c}P \\
\text { Value }\end{array}$ \\
\hline \multicolumn{4}{|l|}{ Admission referral source } \\
\hline Physician or ER & $16(72.7)$ & $9(64.3)$ & .72 \\
\hline Other acute care hospital or other facility & $6(27.3)$ & $5(35.7)$ & \\
\hline \multicolumn{4}{|l|}{ Previous admissions } \\
\hline None & $2(9.1)$ & $7(50.0)$ & .01 \\
\hline$>1$ previous admission & $20(90.9)$ & $7(50.0)$ & \\
\hline \multicolumn{4}{|l|}{ Length of Stay in days (median, IQR) } \\
\hline Hospital & $14.5(9-23)$ & $22(7-39)$ & .31 \\
\hline SICU & $5(2-12)$ & $5(2-27)$ & .62 \\
\hline Prior to SICU admission & $1(0-6)$ & $0(0-2)$ & .23 \\
\hline
\end{tabular}

contained both chlorhexidine and mupirocin resistance determinants. This prevalence is similar to that reported in a study of community-dwelling individuals in St. Louis, Missouri, with a history of skin and soft-tissue infections in which 8 of 755 (1.1\%) of MRSA isolates tested contained both resistance elements. ${ }^{30}$ Further study is needed to determine whether the use of universal decolonization regimens using both chlorhexidine and mupirocin ${ }^{11}$ leads to selection for these dually resistant strains in ICU patients.

The SCCmec type IV mobile genetic element has been associated with community-associated MRSA strains in the United States and elsewhere, ${ }^{36}$ whereas isolates with SCCmec type II have classically been hospital-associated strains. The proportion of MRSA nasal isolates containing the SCCmec type IV mobile genetic element increased steadily over the 8-year study period. This finding is consistent with results from other healthcare facilities, ${ }^{37,38}$ suggesting a shift in epidemiology and that community-associated MRSA strains are now widely disseminated in healthcare facilities.

The present study has limitations inherent to its retrospective design and the use of patient isolates from a single-center site. We were unable to test all the MRSA isolates collected during the study period due to limited resources. However, our random sampling methodology generated a sample with adequate power $(\beta=0.8)$, which was representative of the patient population admitted during the study period. All of the isolates evaluated in this study were recovered from the anterior nares; thus, we do not know the prevalence of $q a c A / B$ in MRSA isolates recovered from other body sites. We did not evaluate phenotypic tolerance to chlorhexidine; therefore, we may have underestimated less common mechanisms of chlorhexidine tolerance. ${ }^{39,40}$ In addition, we do not know the MIC or minimal bactericidal concentration (MBC) of the strains in this study possessing $q a c A / B$. Chlorhexidine tolerance among Gram-negative bacteria was not examined in our study. Our study was performed in a single ICU; thus, generalizability of results to other facilities may be limited.
Our study has several strengths, including a long follow-up period to evaluate the prevalence rate, the use of both phenotypic and genotypic methods to assess mupirocin resistance, a standardized surveillance protocol for collection of MRSA nasal isolates, and a well-established chlorhexidine bathing program in the ICU.

In conclusion, prevalence of $q a c A / B$ associated with chlorhexidine tolerance did change over time among colonizing MRSA isolates over the 8-year period of daily patient bathing with chlorhexidine soap; however, this was not a linear relationship. This change in the frequency of qac $A / B$ genes is most likely due to patients in those years being exposed in prior admissions. The prevalence of MRSA with SCCmec type IV increased over the study period. Further studies are needed to determine whether other ICU-based decolonization strategies, such as universal treatment with chlorhexidine and intranasal mupirocin, will result in selection of co-resistant isolates.

\section{ACKNOWLEDGMENTS}

We thank Dr. Margaret Olsen for her valuable advice on study design and the Barnes-Jewish Hospital Clinical Microbiology laboratory for ongoing efforts to support infection prevention and surveillance programs at Barnes-Jewish Hospital.

Financial support: This work was supported by the Prevention Epicenter Program from the Center for Disease Control and Prevention (1U54CK000 162-01).

Potential conflicts of interest: D.K.W. has served a consultant to Centene Corporation, Sagentia, and Novaerus Corporation. C.A.B. has served a consultant to ThermoFisher. J.E.M. has served a consultant Astra-Zeneca, Cubist, Pfizer, Merck and Bayer, and has received grant support from Astra-Zeneca, Merck and Bayer. All other authors report no conflicts of interest relevant to this article.

Address correspondence to: David K. Warren MD, MPH, 660 S. Euclid Ave., Campus Box 8051, St. Louis, MO 63110 (dwarren@dom.wustl.edu).

\section{REFERENCES}

1. Chambers HF. The changing epidemiology of Staphylococcus aureus? Emerg Infect Dis 2001;7:178-182. 
2. Klevens RM, Morrison MA, Nadle J, et al. Invasive methicillinresistant Staphylococcus aureus infections in the United States. JAMA 2007;298:1763-1771.

3. Magill SS, Edwards JR, Bamberg W, et al. Multistate pointprevalence survey of health care-associated infections. $N$ Engl J Med 2014;370:1198-1208.

4. Cosgrove SE. The relationship between antimicrobial resistance and patient outcomes: mortality, length of hospital stay, and health care costs. Clin Infect Dis 2006;42(Suppl 2): S82-S89.

5. de Kraker ME, Davey PG, Grundmann H. Mortality and hospital stay associated with resistant Staphylococcus aureus and Escherichia coli bacteremia: estimating the burden of antibiotic resistance in Europe. PLoS Med 2011;8:e1001104.

6. Huang SS, Platt R. Risk of methicillin-resistant Staphylococcus aureus infection after previous infection or colonization. Clin Infect Dis 2003;36:281-285.

7. Safdar N, Bradley EA. The risk of infection after nasal colonization with Staphylococcus aureus. Am J Med 2008;121: 310-315.

8. Honda H, Krauss MJ, Coopersmith CM, et al. Staphylococcus aureus nasal colonization and subsequent infection in intensive care unit patients: does methicillin resistance matter? Infect Control Hosp Epidemiol 2010;31:584-591.

9. Kallen $\mathrm{AJ}, \mathrm{Mu} \mathrm{Y}$, Bulens $\mathrm{S}$, et al. Health care-associated invasive MRSA infections, 2005-2008. JAMA 2010;304:641-648.

10. Burton DC, Edwards JR, Horan TC, Jernigan JA, Fridkin SK. Methicillin-resistant Staphylococcus aureus central line-associated bloodstream infections in US intensive care units, 1997-2007. JAMA 2009;301:727-736.

11. Huang SS, Septimus E, Kleinman K, et al. Targeted versus universal decolonization to prevent ICU infection. $N$ Engl J Med 2013;368:2255-2265.

12. Climo MW, Wong ES. Daily chlorhexidine bathing and hospitalacquired infection. N Engl J Med 2013;368:2332.

13. Viray MA, Morley JC, Coopersmith CM, Kollef MH, Fraser VJ, Warren DK. Daily bathing with chlorhexidine-based soap and the prevention of Staphylococcus aureus transmission and infection. Infect Control Hosp Epidemiol 2014;35:243-250.

14. Mayer S, Boos M, Beyer A, Fluit AC, Schmitz FJ. Distribution of the antiseptic resistance genes qacA, qacB and $\mathrm{qacC}$ in 497 methicillin-resistant and -susceptible European isolates of Staphylococcus aureus. J Antimicrob Chemother 2001;47:896-897.

15. Paulsen IT, Brown MH, Littlejohn TG, Mitchell BA, Skurray RA. Multidrug resistance proteins QacA and $\mathrm{QacB}$ from Staphylococcus aureus: membrane topology and identification of residues involved in substrate specificity. Proc Natl Acad Sci USA 1996;93:3630-3635.

16. McDonnell G, Russell AD. Antiseptics and disinfectants: activity, action, and resistance. Clin Microbiol Rev 1999;12:147-179.

17. Sheng WH, Wang JT, Lauderdale TL, Weng CM, Chen D, Chang SC. Epidemiology and susceptibilities of methicillin-resistant Staphylococcus aureus in Taiwan: emphasis on chlorhexidine susceptibility. Diagn Microbiol Infect Dis 2009;63:309-313.

18. Vali L, Davies SE, Lai LL, Dave J, Amyes SG. Frequency of biocide resistance genes, antibiotic resistance and the effect of chlorhexidine exposure on clinical methicillin-resistant Staphylococcus aureus isolates. J Antimicrob Chemother 2008;61: 524-532.
19. Lee AS, Macedo-Vinas M, Francois P, et al. Impact of combined low-level mupirocin and genotypic chlorhexidine resistance on persistent methicillin-resistant Staphylococcus aureus carriage after decolonization therapy: a case-control study. Clin Infect Dis 2011;52:1422-1430.

20. Batra R, Cooper BS, Whiteley C, Patel AK, Wyncoll D, Edgeworth JD. Efficacy and limitation of a chlorhexidine-based decolonization strategy in preventing transmission of methicillin-resistant Staphylococcus aureus in an intensive care unit. Clin Infect Dis 2010;50:210-217.

21. Longtin J, Seah C, Siebert K, et al. Distribution of antiseptic resistance genes qacA, qacB, and smr in methicillin-resistant Staphylococcus aureus isolated in Toronto, Canada, from 2005 to 2009. Antimicrob Agents Chemother 2011;55:2999-3001.

22. Hetem DJ, Bonten MJ. Clinical relevance of mupirocin resistance in Staphylococcus aureus. J Hosp Infect 2013;85:249-256.

23. CLSI. Performance Standards for Antimicrobial Susceptibility Testing; 22nd Information Supplement. CLS document 32, M100-S22. Wayne, PA: Clinical and Laboratory Standards Institute, 2012.

24. Conly JM, Johnston BL. Mupirocin-are we in danger of losing it? Can J Infect Dis 2002;13:157-159.

25. Miller MA, Dascal A, Portnoy J, Mendelson J. Development of mupirocin resistance among methicillin-resistant Staphylococcus aureus after widespread use of nasal mupirocin ointment. Infect Control Hosp Epidemiol 1996;17:811-813.

26. Seah C, Alexander DC, Louie L, et al. MupB, a new high-level mupirocin resistance mechanism in Staphylococcus aureus. Antimicrob Agents Chemother 2012;56:1916-1920.

27. Walker ES, Vasquez JE, Dula R, Bullock H, Sarubbi FA. Mupirocin-resistant, methicillin-resistant Staphylococcus aureus: does mupirocin remain effective? Infect Control Hosp Epidemiol 2003;24:342-346.

28. Simor AE, Phillips E, McGeer A, et al. Randomized controlled trial of chlorhexidine gluconate for washing, intranasal mupirocin, and rifampin and doxycycline versus no treatment for the eradication of methicillin-resistant Staphylococcus aureus colonization. Clin Infect Dis 2007;44:178-185.

29. Jones JC, Rogers TJ, Brookmeyer P, et al. Mupirocin resistance in patients colonized with methicillin-resistant Staphylococcus aureus in a surgical intensive care unit. Clin Infect Dis 2007;45:541-547.

30. Fritz SA, Hogan PG, Camins BC, et al. Mupirocin and chlorhexidine resistance in Staphylococcus aureus in patients with community-onset skin and soft tissue infections. Antimicrob Agents Chemother 2013;57:559-568.

31. Warren DK, Guth RM, Coopersmith CM, Merz LR, Zack JE, Fraser VJ. Epidemiology of methicillin-resistant Staphylococcus aureus colonization in a surgical intensive care unit. Infect Control Hosp Epidemiol 2006;27:1032-1040.

32. CLSI. Performance Standards for Antimicrobial Susceptibility Testing; 23rd Information Supplement. CLS document 33. Wayne, PA: Clinical and Laboratory Standards Institute, 2013.

33. Zhang K, Sparling J, Chow BL, et al. New quadriplex PCR assay for detection of methicillin and mupirocin resistance and simultaneous discrimination of Staphylococcus aureus from coagulasenegative staphylococci. J Clin Microbiol 2004;42:4947-4955.

34. Boye K, Bartels MD, Andersen IS, Moller JA, Westh H. A new multiplex PCR for easy screening of methicillin-resistant Staphylococcus aureus SCCmec types I-V. Clin Microbiol Infect 2007;13:725-727. 
35. Mathers AJ, Cox HL, Kitchel B, et al. Molecular dissection of an outbreak of carbapenem-resistant enterobacteriaceae reveals intergenus KPC carbapenemase transmission through a promiscuous plasmid. MBio 2011;2:e00204-e00211.

36. Deresinski S. Methicillin-resistant Staphylococcus aureus: an evolutionary, epidemiologic, and therapeutic odyssey. Clin Infect Dis 2005;40:562-573.

37. Huang YH, Tseng SP, Hu JM, Tsai JC, Hsueh PR, Teng LJ. Clonal spread of SCCmec type IV methicillin-resistant Staphylococcus aureus between community and hospital. Clin Microbiol Infect 2007;13:717-724.
38. Nair N, Kourbatova E, Poole K, et al. Molecular epidemiology of methicillin-resistant Staphylococcus aureus (MRSA) among patients admitted to adult intensive care units: the STAR ${ }^{\star} \mathrm{ICU}$ trial. Infect Control Hosp Epidemiol 2011;32:1057-1063.

39. Ye HF, Zhang M, O'Donoghue M, Boost M. Are qacG, qacH and qacJ genes transferring from food isolates to carriage isolates of staphylococci? J Hosp Infect 2012;80:95-96.

40. Zmantar T, Kouidhi B, Miladi H, Bakhrouf A. Detection of macrolide and disinfectant resistance genes in clinical Staphylococcus aureus and coagulase-negative staphylococci. BMC Res Notes 2011;4:453. 